\title{
No Dilemma at all: The Importance of Liberal Education in Developing Skills for Employability
}

\author{
D. Bruce MacKay \\ University of Lethbridge
}

Some suggest there is a dilemma in post-secondary education between the tidal pulls of career-or disciplinary-oriented education and liberal education. A survey of University of Lethbridge alumni indicated that they found their liberal education important for developing skills that are valuable in life and work after graduation. Specific skills the Conference Board of Canada (2000) identified as important for employment success were indeed skills which alumni say they developed during their liberal education experience. I argue there is no dilemma at all and that liberal education does provide skills for employment success.

A climate characterized by global financial instability, budgetary belt-tightening, and stringent public accountability has certainly contributed to calls for reevaluating the value and purpose of post-secondary education and, especially, liberal education. On the one hand, some suggest that post-secondary education should aim to provide students with specialized knowledge and credentials necessary for employment. Margarent Wente (2009), a columnist for The Globe and Mail, expresses this view when she writes that, "a vast proportion of the student body neither wants nor needs a traditional liberal education anyway. They have no desire to sit at the feet of cloistered masters debating truth and beauty. They are essentially there for the credentials." On the other hand, many argue that traditional lib- eral education, with its emphasis on learning from the classical thinkers of western civilization and discussing fundamental issues such as the nature of beauty and truth, continues to be the best way to prepare well-rounded individuals for living a good and fulfilling life.

My argument is that there is no dilemma. Liberal education does develop skills and abilities that are valuable in life and in the work place. Evidence gathered from graduates of an institution with an explicit liberal education philosophy, the University of Lethbridge, shows that they found their liberal education experience was important for developing skills necessary for success in the workplace.

Debate about the aims of education is not new. In 5th century BC, Athens educators were divided. Some felt education should develop the skills 
of oratory and rhetoric, skills necessary for participation in Athenian democracy. Though a credential was not the outcome, the purpose was very pragmatic since the arguments and debates presented by "orators" contributed to the democratic decision making processes of the Athenian city state. Other Greek educators, however, felt that the purpose of education was to develop fundamental insights into wisdom and truth. For these thinkers, the pursuit of truth was a higher virtue that liberated the mind, releasing it from the "shadowy cave of ignorance" (Kimball, 1986).

Kimball (1986) suggests that these tides of emphasis have ebbed and flowed over the years. At times, the orators' view has risen to dominance with its emphasis on the practical value of education. At other times, the philosophers' tide has dominated and the oratorial stream has ebbed so that liberal education has emphasized the search for beauty, truth, and knowledge for the sake of knowledge rather than teaching for practical ends.

By the 18 th century, the aim of post-secondary education in the United Kingdom was to develop the civilized and cultured man of good taste (Rothblatt, 1976). The British trajectory of liberal education was perhaps more influential for Canada than it was in the United States. In contrast to American universities' more radical understanding of liberty, which emphasized the oratorial tradition, early Canadian universities emphasized what Kimball (1986) calls the philosophical tradition. Indeed, the founders of the University of New Brunswick (where the 2009 STLHE conference was held), recognizing that the new American nation would provide instruction only in revolutionary "Principles contrary to the British Constitution' and that the cost of an overseas education would be prohibitive, urged the representatives of the British government to consider the 'founding of a College... where Youth may receive a virtuous Education' in such things as 'Religion, Literature, Loyalty, \& good Morals...”' (University of New Brunswick, n.d.).

Through the 19th and into the 20th centuries the approach to liberal education as a "general" education based primarily on reading the classics and learning received knowledge was eventually surpassed by rising professionalism. Professionalism brought with it disciplinary specialization, research, and the quest for progress and new knowledge of more practical application.

Are these two positions mutually exclusive? Does post-secondary education really face a dilemma between the tidal pulls of career- or disciplinary-oriented education and liberal education? The answer, in my mind, is no. This also seems to be the view of University of Lethbridge alumni.

Over the past few years, I have gathered anecdotal evidence from former students through letters and conversations which indicated that many alumni found their liberal education experience was not useless but, in fact, important for developing skills they found valuable in their lives and work after graduation. To better assess these views, my colleague, Dr. Jennifer Mather (Psychology), and I developed a questionnaire to explore perceptions of University of Lethbridge alumni about the value of their liberal education experience.

We prepared a survey of skills adapted from a pamphlet produced by the Conference Board of Canada titled Employability Skills 2000+. The survey questions (approved by the University of Lethbridge Human Research Ethics Committee) asked alumni to look back on their liberal education experience at the University and evaluate how important it was to their development of particular skills. The questions inquired about skills in three different areas: individual cognitive/intellectual skills (11 questions); self-reflection skills (8 questions); and individual management skills (5 questions). A link to the survey was sent in an email message to all alumni on the University's Alumni Relations email list. The message reached 9157 alumni (32.5\% of all University of Lethbridge alumni). We received 961 responses (10.5\% of those emailed). We analyzed a total of 780 responses (8.5\% of those emailed; $2.6 \%$ of all alumni). Duplicate, incomplete, and responses which did not differentiate on the response scale were deleted from the analysis.

Alumni indicated their responses on a seven point Likert scale, ranging from 1 (not important) to 7 (very important). In the aggregate, $70 \%$ of all respondents rated the importance of their liberal 
education experience in the upper three categories (response numbers 5, 6, and 7; see Figure 1). In total $19 \%$ rated the value of their liberal education as very important (response 7 on the Likert scale). Just 16\% of respondents rated the importance of liberal education in the lower three categories.

Figure 2 compares the responses to the 24 questions which we adapted from the Employability Skills 2000+ pamphlet. The bars represent an average of the total responses to each of the seven points on the Likert scale. Each bar thus provides only a handy indicator of the average weight of all choices made by alumni on each question. We can note that "written communication," "personal attributes," and "information retrieval" skills were areas where liberal education was seen to be most important while "numeracy," "ability to work cross-culturally," and "confidence in dealing with challenges" were areas where liberal education was reported to be least important. Overall, however, it is clear that the liberal education experience of alumni was viewed generally as being important for developing these skills when broken down by question.

Further distinctions emerged when we broke down the responses by major. Bachelor of Arts and Bachelor of Education alumni rated their liberal education experience as being more important for developing these skills than did their peers with Bachelor of Science or Bachelor of Management degrees (Figure 3).

We note that $11 \%$ of Bachelor of Education (BEd) and $14 \%$ of Bachelor of Arts (BA) alumni (represented by the two left-most bars in each group) rated the value of their liberal education experience on the not important side of the seven point Likert scale (response numbers 1, 2, and 3). In comparison, there

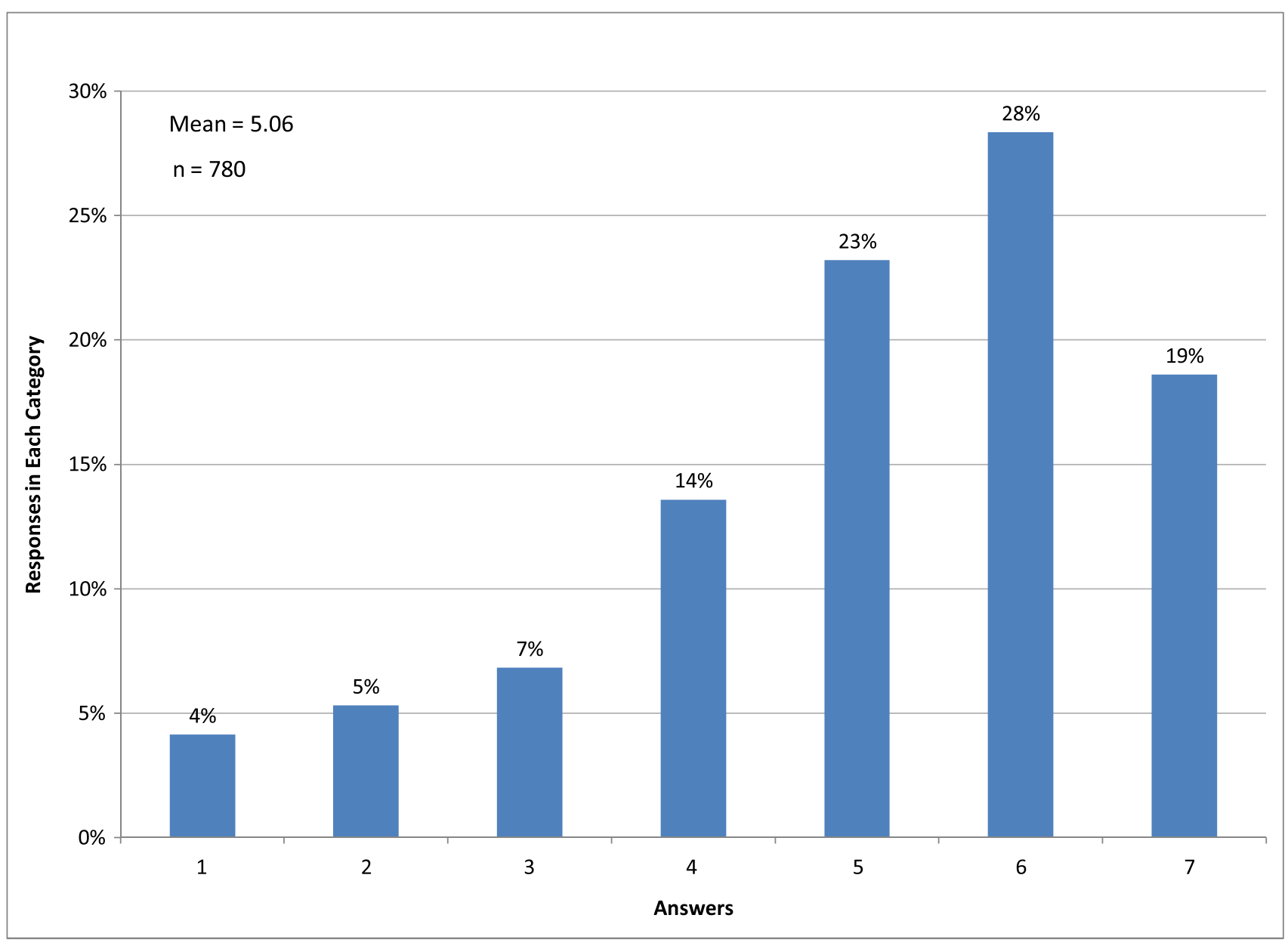

Figure 1

Aggregated Responses 


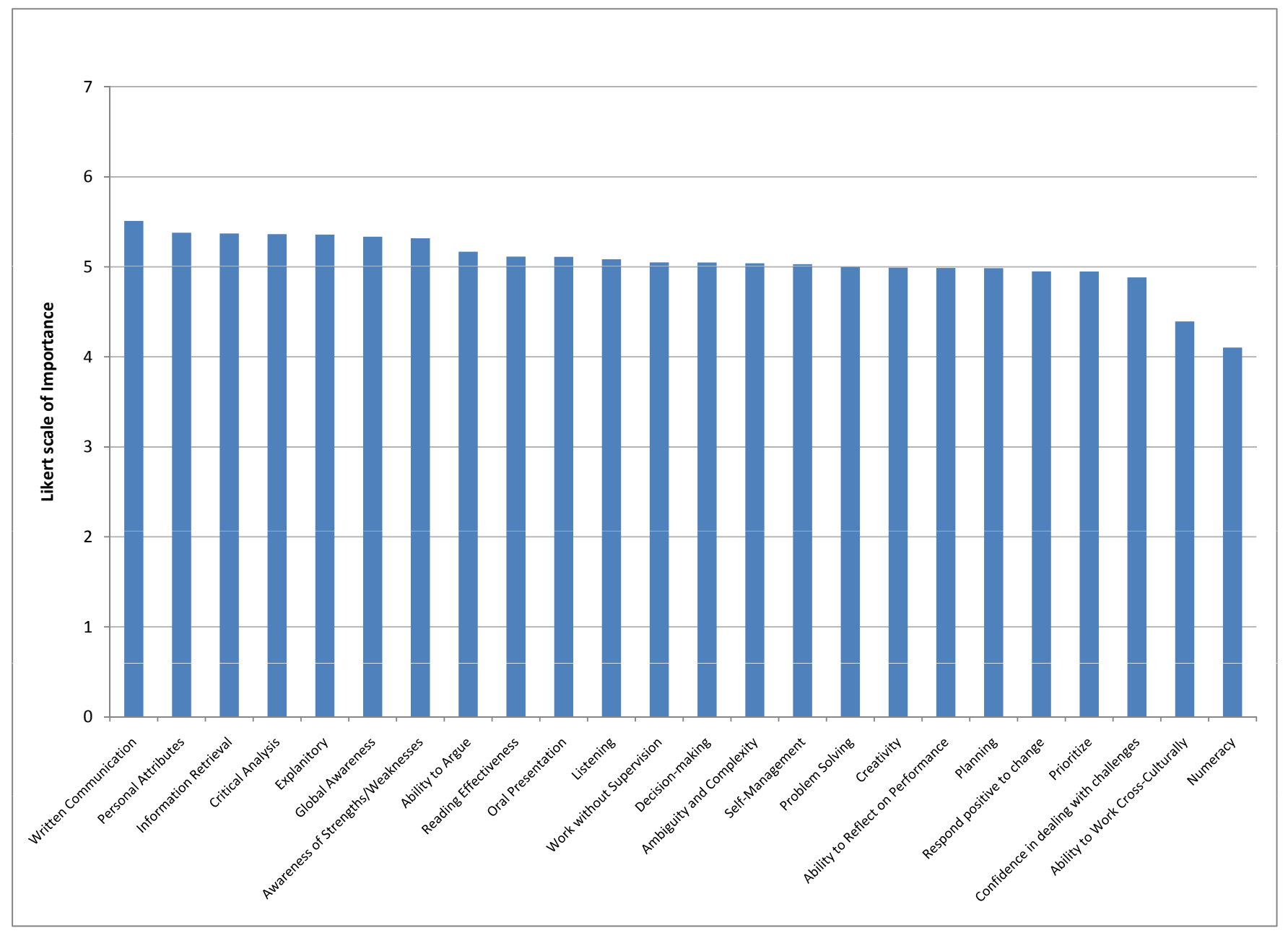

Figure 2

Averages for Each Question

were more alumni with Bachelor of Science (BSc) and Bachelor of Management (BMgt) degrees (represented by the two right-most bars in each group) who rated their liberal education experience as not important (20\% BMgt and 24\% BSc alumni respectively with response numbers 1,2 , and 3 ). On the positive side, $22 \%$ of BEd and $20 \%$ of BA alumni rated the value of their liberal education experience as very important, while only $16 \%$ of BMgt and $15 \%$ of BSc alumni rated it as very important (response number 7).

This difference may be because the values of liberal education are more typically taught in BA and BEd courses than in BMgt and BSc courses. Additional study will be required to determine if this or other factors are at play.

When the results are broken down by year of graduation, we observe another pattern (Figure
4). Alumni who graduated more than 10 years ago (1999 and earlier, represented by the left-most bars in each group for year categories 1, 2, and 3) reported that their liberal education experience was more important than those graduating more recently (2000 through 2008 represented by the right-most bars in each group for year categories 4, 5, and 6). The average response of those graduating in the most recent four years was 4.87, while those who had graduated 10 years ago or earlier produced a mean of 5.10 and higher.

There may be a number of explanations for this pattern. It may be that after 10 years of life and work experience alumni appreciate the value of their liberal education more than they did when they first graduated. More recent graduates may not have yet come to value their experience as much as their older 


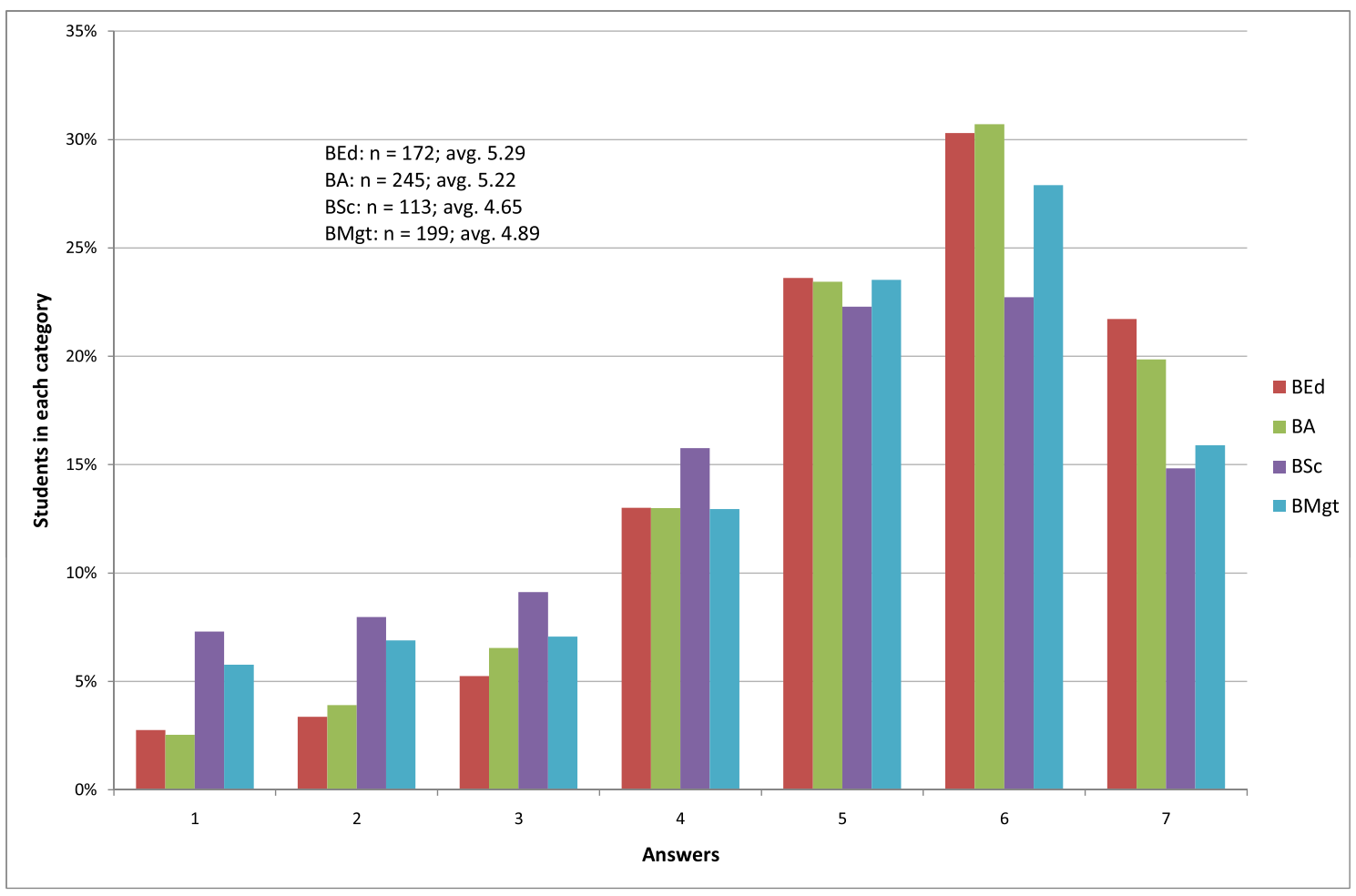

Figure 3

Aggregated Responses by Major

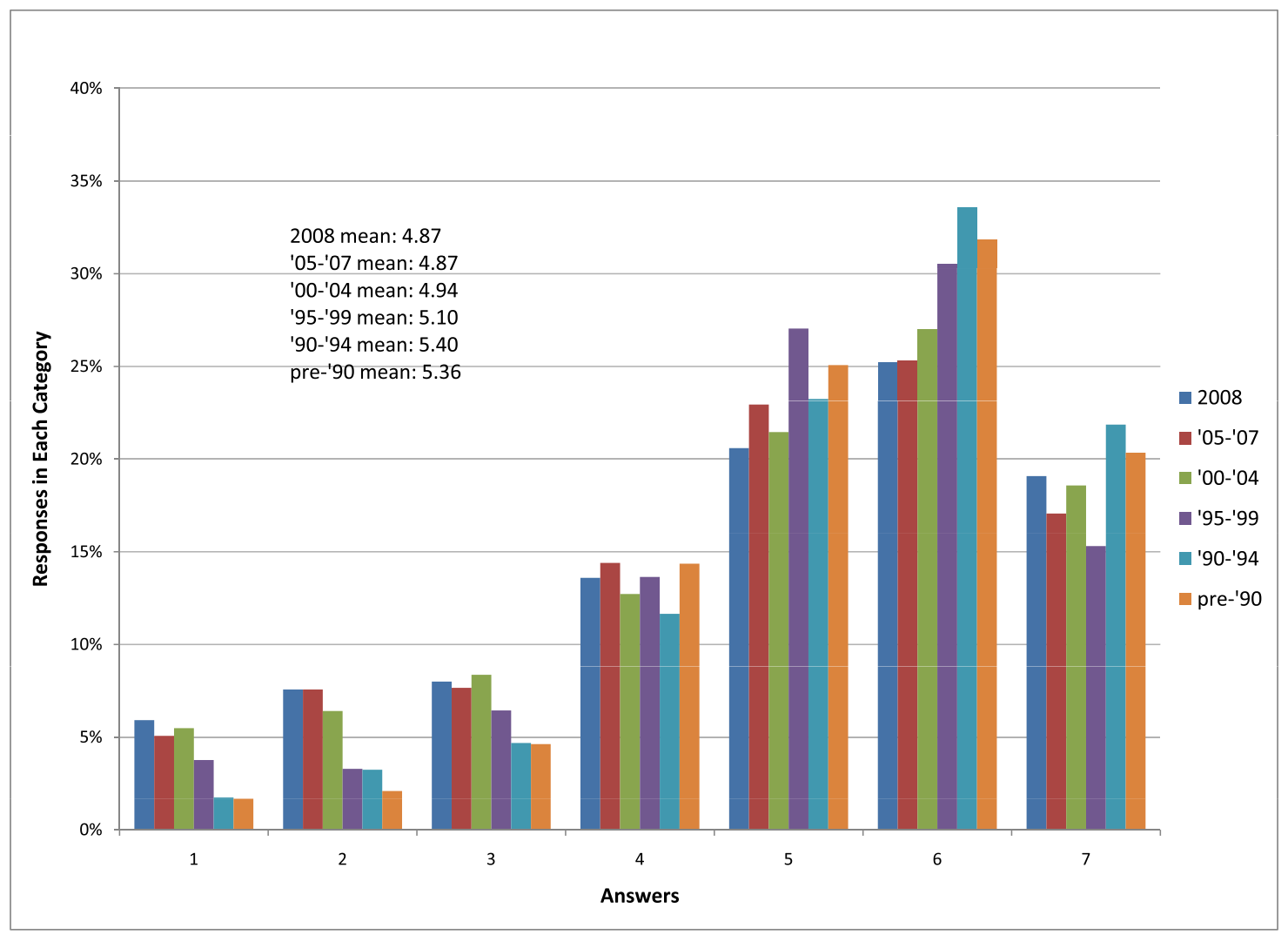

Figure 4

Year of Graduation 
colleagues. Another possibility is that student expectations or teaching methods may have changed over the past years to the point that students who graduated more than 10 years ago had a more favourable experience with liberal education during their years at the University than that had by more recent graduates. As well, it may be possible that after 10 years, a kind of academic amnesia has set in so that older graduates have developed a rosier picture of their liberal education experience than more recent graduates. Further research will provide a clearer picture.

Is there really a dilemma in post-secondary education between the tidal pulls of career- or disciplinary-oriented education and liberal education? I think the evidence from this survey shows that University of Lethbridge alumni have found no dilemma at all. They say that they have found their liberal education to be important for developing the very skills identified by the Conference Board of Canada (2000) as being important for employment success.

As for the tidal pulls within liberal education between Kimball's (1986) two traditions of philosopher and orator, these data show that we need not be shy in arguing that liberal education does contribute to the development of useful skills. Especially in the current economic climate of tight budgets and clear accountability, it may be time to emphasize the orators' tradition and to argue that liberal education does help to provide the skills necessary for success. The problems humanity faces in the future will not be solved by narrow-minded formulaic thinkers or by those who have no practical contribution to make. We need innovative creative thinkers who make connections across disciplinary boundaries and who have the skills to analyze arguments and think critically, to work with other people, and to synthesize data and make good arguments of their own. Liberal education develops these skills, skills that are valuable for employability and for citizenship. In my view, then, there is no dilemma.

\section{References}

Conference Board of Canada. (2000). Employability skills 2000+. [Brochure]. Ottawa, ON: Author.
Kimball, B. (1986). Orators \& philosophers: A history of the idea of liberal education. New York, NY: Teachers College Press.

Rothblatt, S. (1976). Tradition and change in English liberal education: An essay in history and culture. London, UK: Faber \& Faber.

University of New Brunswick. (n.d.). Historical sketch of UNB. Retrieved from http://www.unb.ca/ aboutunb/history/historicalsketch.html

Wente, M. (2009, January 31). Higher education? Aim lower. The Globe and Mail, p. A21.

\section{Biography}

D. Bruce MacKay (Ph.D., Religious Studies, University of Toronto; M.T.S., Biblical Studies, Harvard Divinity School; B.A., Anthropology, University of Lethbridge) has been Coordinator of Liberal Education at the University of Lethbridge since 2003. He is currently interested in the scholarship of teaching and learning and in the way that it applies to liberal education. 